\title{
Influence of Fiber Properties on Shear Failure of Steel Fiber Reinforced Beams Without Web Reinforcement: ANN Modeling
}

Abstract

In this paper, an artificial neural network (ANN-10) model was developed to predict the ultimate shear strength of steel fiber reinforced concrete (SFRC) beams without web reinforcement. ANN-10 is a four-layered feed forward network with a back propagation training algorithm. The experimental data of $70 \mathrm{SFRC}$ beams reported in the technical literature were utilized to train and test the validity of ANN-10. The input layer receives 10 input signals for the fiber properties (type, aspect ratio, length and volume content), section properties (width, overall depth and effective depth) and beam properties (longitudinal reinforcement ratio, compressive strength of concrete and shear span to effective depth ratio). ANN-10 has exhibited excellent predictive performance for both training and testing data sets, with an average of 1.002 for the average of predicted to experimental values. This performance of ANN-10 established the promising potential of Artificial Neural Networks (ANNs) to simulate the complex shear behavior of SFRC beams. ANN-10 was applied to investigate the influence of the fiber volume content, type, aspect ratio and length on the ultimate shear strength of SFRC.

\section{Keywords}

Beams, Fiber reinforced concrete, Shear failure, Steel fiber reinforced concrete (SFRC), Numerical modeling.
Yassir M. Abbas a, 1

M. Iqbal Khan ${ }^{\text {a, } 2 *}$

${ }^{\text {a }}$ Department of Civil Engineering, King Saud University, Riyadh, P. O. Box 800, Riyadh 11421, Saudi Arabia

${ }^{1}$ Email: yabbas@ksu.edu.sa

${ }^{2}$ Email: miqbal@ksu.edu.sa

* Corresponding author

http://dx.doi.org/10.1590/1679-78252851

Received 14.02.2016

In revised form 21.03.2016

Accepted 21.03.2016

Available online 23.03.2016

\section{INTRODUCTION}

Reinforced concrete beams with or without web reinforcement, which are subjected to combined flexural and shear stress, can be prone to instantaneous failure in shear (Roberts and Ho 1982; Dinh 2009). Traditionally, reinforced concrete beams are reinforced with web reinforcement to avoid failure due to tensile-shear stresses. The inclusion of short and discrete steel fibers with an aspect ratio 
(fiber length to diameter) ranging between 20 to 100 in concrete, has been proven to enhance the shear strength by resisting the formation and growth of cracks (Al-Ta'an and Al-Feel 1990). The use of fibers in thin sections and congested reinforcing steel sections is highly beneficial, as it may be difficult to provide conventional web reinforcement. For deep beams and due to the high inclined tensile stresses arising from the shear stresses on vertical planes, shear cracks may propagate rapidly in the web causing a catastrophic failure. However, the understanding of the shear behavior of beams, particularly for deep beams, constitutes a challenging engineering problems, since various modes of failures have been observed for such beams (Roberts and Ho 1982). This problem is complicated by the nonlinear interactions arising from the inclusion of steel fiber in concrete. At present, numerous predictive models for the evaluation of the ultimate shear strength of SFRC beams have been developed based on the regression analysis (Mansour et al. 1986; Sharma 1986; Al-Ta'an and Al-Feel 1990; Khuntia et al. 1999). In such complex problems, which are difficult to be modeled using conventional modeling techniques, the application of ANNs may have a good application potential. ANNs have been introduced to the field of civil engineering as a powerful modeling technique, which has achieved acceptable success in many applications (Hegazy et al. 1998; Perera et al. 2010; Bashir and Ashour 2012; Mashrei et al. 2013; Lee and Lee 2014). ANNs are numerical architectures composed of huge elements of strongly interlocking manufactured elements known as neurons, which simulate the human brain mechanism of learning and solving problems. The construction of the ANN models mainly depends on the actual, adequate and reliable experimental data. ANNs can solve highly non-linear and sophisticated problems, including problems having inaccurate and scattered data (Jha 2007).

In the present literature, the information concerning the use of ANN for the prediction of the ultimate shear strength of SFRC beams is scarce. Naik and Kute (2014) developed an ANN model based on seven and eight input nodes for the prediction of high performance deep SFRC beams. These researchers have used the developed ANN to investigate the influence of the shear span to effective depth ratio of high performance deep SFRC beams. They reported that ANNs are a promising technique to predict the complex shear behavior of SFRC beams in terms of various parameters, which can reduce the cost of the experimental investigations. Using four and five input node ANNs, Adhikari and Mutsuyoshi (2006) predicted the ultimate shear strength of SFRC beams based on the experimental results of the literature. It was reported that the predictive efficiency of the network enhances as the number of input nodes increases. In addition, it was observed that ANNs have better predictive performance compared to regression methods. It is worth noting that considerable research effort has been undertaken to investigate the effects of incorporating steel fibers on the ultimate shear strength of SFRC beams based on the fiber factor, which combines the fiber properties (type, length and aspect ratio). Few reported experimental investigations are available concerning the effect of the fiber volume content on the ultimate shear strength of SFRC with or without web reinforcement (Lim and Oh 1999; Kwak et al. 2002; Cucchiara et al. 2004). In addition, very few researchers have investigated the influence of the individual fiber properties on the ultimate shear strength of SFRC beams without web reinforcement (Dinh 2009). The objectives of this study are: 1) to investigate the potential of using ANNs for the prediction of the ultimate shear strength of SFRC beams, and 2) to investigate the influence of the fiber properties on the ultimate strength of SFRC beams without web reinforcement. 


\section{SIGNIFICANCE OF RESEARCH}

Concrete as a brittle material responds by cracking when subjected to low tensile stresses arising from the shear stresses at the inclined sections of a beam. The failure of beams usually causes catastrophic loss, both human and material, because of its sudden occurrence without a warning. The incorporation of steel fibers in concrete enhances its tensile stress resistance at the post cracking stage of concrete, which increases the ultimate shear strength of SFRC beams. However, the only accurate method for the evaluation of this strength is through the costly experimental testing of full-scale beams. The development of rational numerical methods for the prediction of the fracture behavior of SFRC reduces the cost of experimentation and provides the appropriate tool for the optimal design of SFRC. In addition, investigating the role of the individual fiber properties assists in providing an understanding of the behavior of SFRC beams in shear.

\section{PARAMETERS INFLUENCING THE ULTIMATE SHEAR STRENGTH OF SFRC}

As a conventional reinforced concrete, the ultimate shear strength of SFRC beams without web reinforcement is primarily influenced by: 1) the compressive strength of concrete, 2) the ratio of the longitudinal reinforcement, 3) the shear span to effective depth ratio, and 4) the section dimensions (particularly the effective depth). In addition, the ultimate shear strength of SFRC beams are affected by the properties of the fiber, namely: 1) type, 2) length, 3) aspect ratio, and 4) volume content. Various researchers assumed that the shear resistance of SFRC beams without web reinforcement is based on: 1) the shear force in the untracked compression zone, 2) the aggregate interlock force in the cracked tensile concrete, 3) the dowel force in the main steel, and 4) the contribution of steel fibers in the diagonal crack zone (Al-Ta'an and Al-Feel 1990; Lim and Oh 1999; Dinh 2009). Figure 1 shows the shear resistance forces at the inclined tensile crack of SFRC beam without web reinforcement.

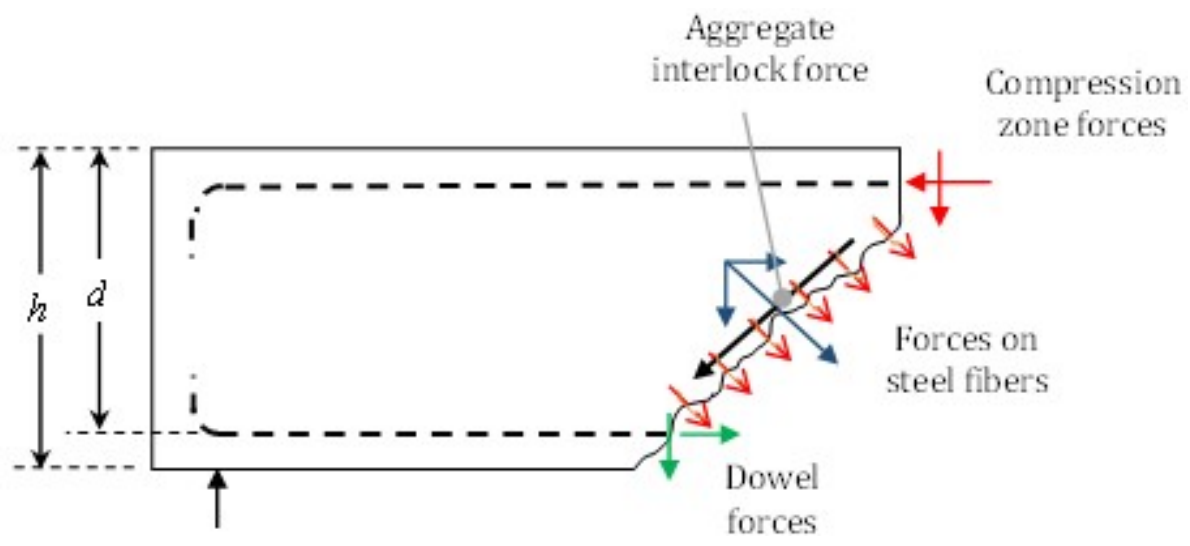

Figure 1: Shear resistance forces at inclined tensile crack of SFRC beam without web

Based on experimental investigations, Khuntia et al. (1999) reported that increasing the compressive strength of concrete drastically enhances the ultimate shear strength of SFRC beams. This was attributed to the enhancement occurring in the fiber-matrix interfacial bond. In contrast, in- 
creasing the shear span to an effective depth ratio drastically reduces the ultimate shear strength of SFRC beams due to the arching behavior. Swamy and Bahia (1985) observed that, the ultimate shear strength of SFRC beams increases as the longitudinal reinforcement increases to a particular value beyond which it decreases. This was attributed to the increase in the longitudinal reinforcement-concrete dowel interactions. The fiber aspect ratio was not reported to affect the ultimate shear strength of SFRC beams. However, various researchers investigated the effect of fiber using the fiber factor suggested by Narayanan and Darwish (1987), which combines the fiber type, aspect ratio and volume content. As reported by these researches, the most significant factor is the fiber volume content.

\section{ARTIFICIAL NEURAL NETWORKS}

In the field of civil engineering, ANNs have achieved a high degree of applicability. Sanand and Saka (2001) developed an ANN to predict the ultimate shear strength of conventional reinforced concrete deep beams. These researchers have shown that the developed ANN has better predictive capability than the equations suggested by the ACI 318 committee. Hegazy et al. (1998) investigated the potential of using ANNs to develop efficient predictive models for the structural behavior of concrete slabs. They reported that ANNs are a useful technique for the reasonable prediction of the behavior of concrete slabs without additional experimental testing.

Due to its simplicity, the multi-layer perceptron ANNs with feed forward and back propagation are mostly utilized in engineering. The input layer receives signals, which treated through the hidden layer, and finally produced in the output layer. The learning process requires the evaluation of the weight of the processing connections and their modality. Mostly, only one hidden layer is enough to correlate highly nonlinear parameters, however, in some cases two or more hidden layers are more efficient (Adhikary and Mutsuyoshi 2006). The major concerns of structural analysis problems, such as predicting different properties of concrete and load carrying capacity, have been solved mostly by using back propagation (Naik and Kute 2014).

\section{DEVELOPMENT OF THE NEURAL NETWORK MODEL}

In this paper, a multilayer feed forward neural network with a back propagation training algorithm was used to develop ANN-10. Figure 2 shows the topology of ANN-10, which has 10 input nodes, two hidden layers with 14 neurons and one output layer. In this figure, the network is represented in the form of a directed graph, in which the nodes represent the processing unit, the straight lines represent the connections, and the arrowhead lines indicate the normal direction of signal flow. In addition, $w_{x, n}$ and $v_{n, y}$ are the weight matrices and $b_{1}$ to $b_{10}$ are the bias vector elements.

In order to achieve the desired outputs, weights (represent connection strength between neurons) and biases were corrected at a constant learning rate using the perceptron learning rule as given by Eqs. (1)-(2). Then, the network error (the difference between calculated and expected target patterns) was back propagated from the output layer to the input layer. The process of correcting the neuron weights and biases was undertaken until the network output arrives at a specific level of accuracy. Once the activities of all the output units were determined, the network computed the errors $E$, which is defined by Eq. (3). 


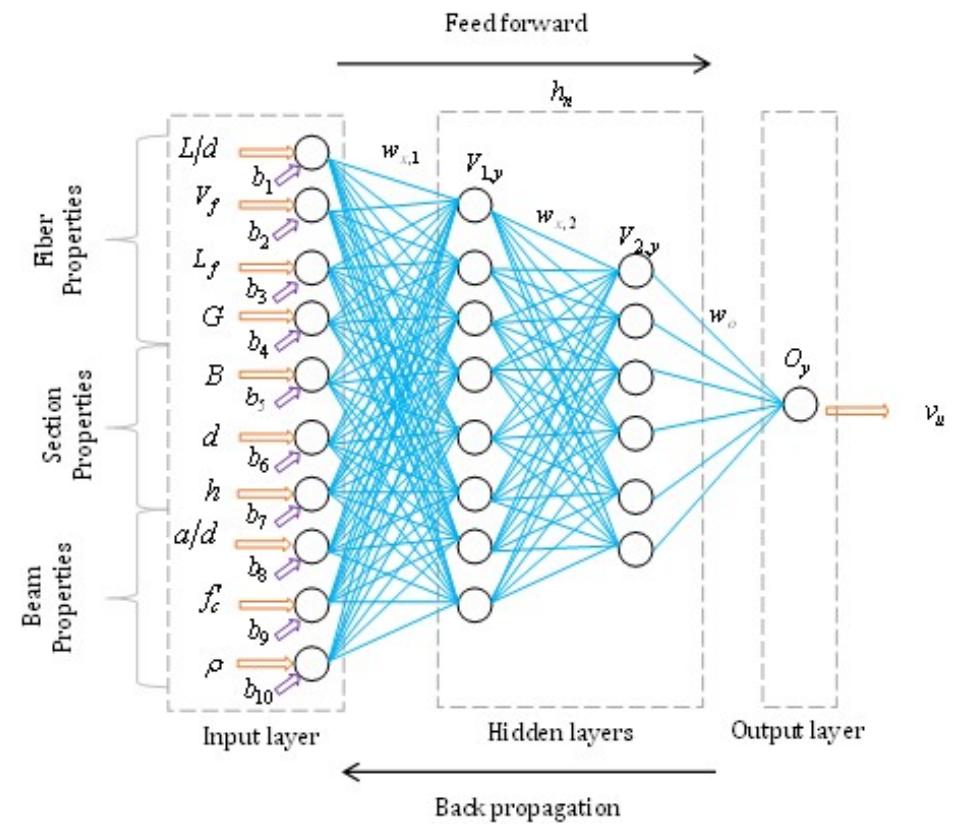

Figure 2: The topology of ANN-10

To accelerate the convergence of the predicted output with the desired output, a sigmoid activation function, $\phi(V)$ as given by Eq. (4), was used to evaluate the values of the hidden and output neurons. Before applying the sigmoid activation function, a linear normalization function, as given by Eq. (5), was applied to scale the input values between zero and one. Eqs. (6)-(7) describes the mode of mathematical operations in the hidden and output layers of ANN-10. It is worth noting that MS Excel was utilized to develop the ANN-10 based on the flow chart given in Figure 3. Moreover, the Optimization Modeling System "Solver" in the MS Excel was used to optimize the developed ANN model. The parameters of the Solver tool were adjusted arbitrary and those result in the minimum mean square error ( $E$ in Eq. 3 ) were adopted.

$$
\begin{gathered}
w_{i}(t+\Delta t)=w_{i}(t)+\Delta w_{i}(t) \\
\Delta w_{i}(t)=\gamma(D-Y) I_{i} \\
E=\sum_{i}\left(D_{i}-Y_{i}\right)^{2} \\
\phi(V)=\frac{1}{1+e^{-\lambda V}} \\
S=\frac{I-I_{\min }}{I_{\max }-I_{\min }} \\
h_{n}=\phi\left(V_{n}\right)=\phi\left(\sum_{x=0}^{M} w_{n, x} i_{x}\right)=\phi\left(\sum_{x=1}^{M} w_{n, x} i_{x}+b_{n}\right)
\end{gathered}
$$




$$
O_{n}=\phi\left(V_{y}\right)=\phi\left(\sum_{x=0}^{N} v_{y, n} h_{n}\right)=\phi\left(\sum_{x=0}^{N} v_{y, n} h_{n}+b_{y}\right)
$$

In Eqs. (1)-(7), $t$ stands for time, $D$ is the desired output, $Y$ is the actual output, $I_{i}$ is the $i^{\text {th }}$ input signal, $\gamma$ is the learning rate, $V$ is the value of the normalized input or output, $i_{X}$ is the transmitted value from $x^{\text {th }}$ input neuron, $i^{\text {th }}, h_{n}$ is the activity level generated at the $n^{\text {th }}$ hidden neuron, $O_{n}$ is the activity level generated at the $y^{\text {th }}$ output neuron, $w_{n, x}$ and $v_{y, n}$ are weights on the connections to the hidden and output layers of neurons, respectively. Finally, $b_{n}, b_{y}$ and $\phi(V)$ are weighted biases and activation function.

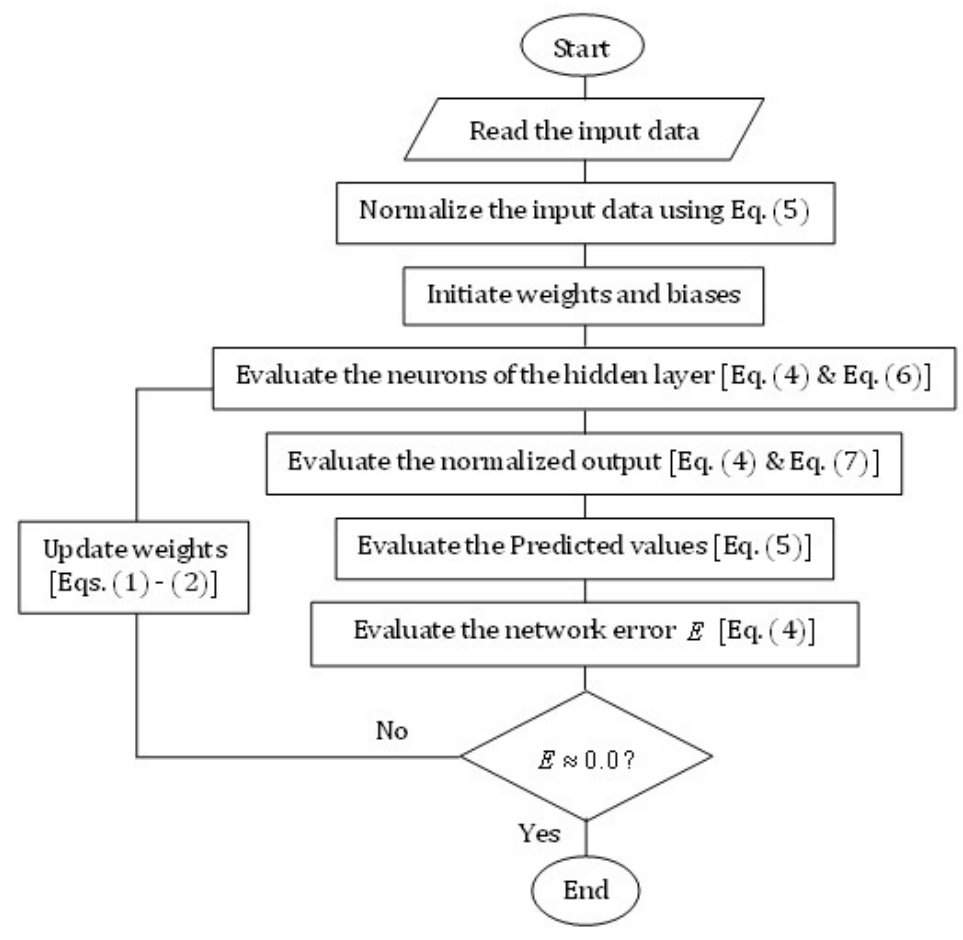

Figure 3: Flow chart for development of ANN-10

\section{EXPERIMENTAL DATA}

In this study, the experimental data utilized to train and test the performance of ANN-10 were the experimental test results of 70 SFRC beams collected from 11 published reports (Roberts and Ho 1982; Swamy and Bahia 1985; Lim et al. 1987; Swamy et al. 1993; Tan et al. 1993; Adebar et al. 1997; Lim and Oh 1999; Kwak et al. 2002; Cucchiara et al. 2004; Parra-Montesinos 2006; Dinh 2009) as given in Table 1. The collected data included: 1) $G$ (the fiber geometry code, which is 1 for straight, 2 for crimped, 3 for hooked fibers), 2) $V_{f}$ (the fiber volume content), 3 ) $L_{f} / d_{f}$ (the fiber aspect ratio), 4) $L_{f}$ (the fiber length), 5) $h$ (the beam section overall depth), 6) $b$ (the beam 
section width), 7) $d$ (the beam section effective depth), 8) a/d (the shear span to effective depth ratio), 9) $\rho$ (the ration of the longitudinal reinforcement, 10) $f_{c}^{\prime}$ (the concrete compressive strength) and 11) $v_{u}=V_{u} / b h$ (the ultimate shear strength of the beam).

It should be noted that the cylindrical compressive strength of concrete was evaluated as $80 \%$ of the cubic compressive strength. Data pre-processing was carried out on the collected results of the experimental data to exclude the inconsistent data points. As the objective of this paper is to predict the ultimate shear strength of FRC beams without web reinforcement, beams that failed in the flexure mode were excluded. In addition, high strength and ultra-high beams having high strength and ultra-high compressive strength concrete $\left(f_{c}^{\prime}>60 \mathrm{MPa}\right)$ were also excluded. Then, the collected data were subdivided into two sets, $70 \%$ for the training data set (49 data points), and $30 \%$ for the testing data set (21 data points).

\begin{tabular}{|c|c|c|c|c|c|c|c|c|c|c|c|c|}
\hline No & $L_{f} / d_{f}$ & $\begin{array}{l}\rho_{f} \\
(\%) \\
\end{array}$ & $\begin{array}{c}L_{f} \\
(\mathrm{~mm}) \\
\end{array}$ & $G$ & $\begin{array}{c}h \\
(\mathrm{~mm}) \\
\end{array}$ & $\begin{array}{c}b \\
(\mathrm{~mm}) \\
\end{array}$ & $\begin{array}{c}d \\
(\mathrm{~mm})\end{array}$ & $\begin{array}{c}f_{c^{\prime}} \\
(\mathrm{MPa}) \\
\end{array}$ & $a / d$ & $\begin{array}{c}P \\
(\%) \\
\end{array}$ & $v_{u}$ & Ref. \\
\hline 1 & 60 & 1.00 & 42 & 1 & 180 & 100 & 140 & 38.69 & 0.31 & 2.23 & 4.490 & $\begin{array}{l}\text { Lim and } \\
\text { Oh } 1999\end{array}$ \\
\hline 2 & 100 & 0.00 & 38 & 1 & 200 & 50 & 170 & 31.36 & 2.41 & 2.10 & 2.760 & \multirow{5}{*}{$\begin{array}{c}\text { Roberts } \\
\text { and Ho } \\
1982\end{array}$} \\
\hline 3 & 100 & 0.85 & 38 & 1 & 200 & 50 & 170 & 31.28 & 2.41 & 2.10 & 3.860 & \\
\hline 4 & 100 & 1.30 & 38 & 1 & 200 & 50 & 170 & 59.88 & 2.41 & 2.10 & 4.260 & \\
\hline 5 & 100 & 0.00 & 38 & 1 & 200 & 50 & 170 & 31.36 & 1.62 & 2.10 & 5.330 & \\
\hline 6 & 100 & 0.85 & 38 & 1 & 200 & 50 & 170 & 31.28 & 1.62 & 2.10 & 5.990 & \\
\hline 7 & 60 & 1.00 & 30 & 3 & 250 & 150 & 219 & 40.85 & 2.80 & 6.59 & 2.934 & \multirow{4}{*}{$\begin{array}{l}\text { Cucchiara } \\
\text { et al. } 2004\end{array}$} \\
\hline 8 & 60 & 2.00 & 30 & 3 & 250 & 150 & 219 & 43.23 & 2.80 & 6.59 & 3.145 & \\
\hline 9 & 60 & 1.00 & 30 & 3 & 250 & 150 & 219 & 40.85 & 2.00 & 6.59 & 3.503 & \\
\hline 10 & 60 & 2.00 & 30 & 3 & 250 & 150 & 219 & 43.23 & 2.00 & 6.59 & 3.516 & \\
\hline 11 & 60 & 1.00 & 30 & 3 & 457 & 152 & 381 & 38.10 & 3.50 & 1.96 & 3.030 & \multirow{6}{*}{$\begin{array}{c}\text { Parra- } \\
\text { Montesinos } \\
2006\end{array}$} \\
\hline 12 & 60 & 1.00 & 30 & 3 & 457 & 152 & 381 & 38.10 & 3.50 & 1.96 & 3.090 & \\
\hline 13 & 60 & 1.00 & 30 & 3 & 457 & 152 & 381 & 38.10 & 3.50 & 2.67 & 3.460 & \\
\hline 14 & 60 & 1.00 & 30 & 3 & 457 & 152 & 381 & 38.10 & 3.50 & 2.67 & 2.530 & \\
\hline 15 & 60 & 1.50 & 30 & 3 & 457 & 152 & 381 & 31.00 & 3.40 & 2.67 & 2.560 & \\
\hline 16 & 60 & 1.50 & 30 & 3 & 457 & 152 & 381 & 31.00 & 3.40 & 2.67 & 3.370 & \\
\hline 17 & 60 & 1.50 & 30 & 3 & 457 & 152 & 381 & 49.90 & 3.40 & 2.67 & 3.280 & \multirow{4}{*}{$\begin{array}{l}\text { Parra- } \\
\text { Montesin- } \\
\text { os } 2006\end{array}$} \\
\hline 18 & 60 & 1.50 & 30 & 3 & 457 & 152 & 381 & 49.90 & 3.40 & 2.67 & 3.260 & \\
\hline 19 & 60 & 1.00 & 30 & 3 & 457 & 152 & 381 & 49.20 & 3.40 & 2.67 & 2.970 & \\
\hline 20 & 60 & 1.00 & 30 & 3 & 457 & 152 & 381 & 49.20 & 3.40 & 2.67 & 3.770 & \\
\hline 21 & 60 & 0.75 & 30 & 3 & 610 & 152 & 558 & 54.10 & 1.60 & 2.12 & 3.240 & \multirow{6}{*}{$\begin{array}{c}\text { Adebar et } \\
\text { al. } 1997\end{array}$} \\
\hline 22 & 60 & 1.50 & 30 & 3 & 610 & 152 & 558 & 49.90 & 1.60 & 2.12 & 3.810 & \\
\hline 23 & 60 & 0.40 & 30 & 3 & 610 & 152 & 558 & 54.80 & 1.60 & 2.12 & 2.400 & \\
\hline 24 & 60 & 0.60 & 30 & 3 & 610 & 152 & 558 & 56.50 & 1.60 & 2.12 & 2.730 & \\
\hline 25 & 100 & 0.40 & 50 & 3 & 610 & 152 & 558 & 46.90 & 1.60 & 2.12 & 2.900 & \\
\hline 26 & 100 & 0.60 & 50 & 3 & 610 & 152 & 558 & 40.80 & 1.60 & 2.12 & 2.790 & \\
\hline 27 & 63 & 0.50 & 50 & 3 & 250 & 125 & 212 & 63.80 & 2.00 & 1.46 & 5.090 & \multirow[t]{2}{*}{$\begin{array}{c}\text { Kwak et } \\
\text { al. } 2002\end{array}$} \\
\hline 27 & 63 & 0.50 & 50 & 3 & 250 & 125 & 212 & 63.80 & 2.00 & 1.46 & 5.090 & \\
\hline
\end{tabular}

Table 1: Experimental data. 


\begin{tabular}{|c|c|c|c|c|c|c|c|c|c|c|c|c|}
\hline No & $L_{f} / d_{f}$ & $\begin{array}{c}\rho_{f} \\
(\%)\end{array}$ & $\begin{array}{c}L_{f} \\
(\mathrm{~mm}) \\
\end{array}$ & $G$ & $\begin{array}{c}h \\
(\mathrm{~mm}) \\
\end{array}$ & $\begin{array}{c}b \\
(\mathrm{~mm}) \\
\end{array}$ & $\begin{array}{c}d \\
(\mathrm{~mm}) \\
\end{array}$ & $\begin{array}{c}f_{c^{\prime}} \\
(\mathrm{MPa}) \\
\end{array}$ & $a / d$ & $\begin{array}{c}\rho \\
(\%) \\
\end{array}$ & $v_{u}$ & Ref. \\
\hline 28 & 63 & 0.75 & 50 & 3 & 250 & 125 & 212 & 68.60 & 2.00 & 1.46 & 5.440 & \multirow{9}{*}{$\begin{array}{l}\text { Kwak et } \\
\text { al. } 2002\end{array}$} \\
\hline 29 & 63 & 0.50 & 50 & 3 & 250 & 125 & 212 & 63.80 & 3.00 & 1.46 & 3.090 & \\
\hline 30 & 63 & 0.75 & 50 & 3 & 250 & 125 & 212 & 68.60 & 3.00 & 1.46 & 3.400 & \\
\hline 31 & 63 & 0.50 & 50 & 3 & 250 & 125 & 212 & 63.80 & 4.00 & 1.46 & 2.410 & \\
\hline 32 & 63 & 0.75 & 50 & 3 & 250 & 125 & 212 & 68.60 & 4.00 & 1.46 & 2.740 & \\
\hline 33 & 63 & 0.50 & 50 & 3 & 250 & 125 & 212 & 30.80 & 4.00 & 1.46 & 4.040 & \\
\hline 34 & 63 & 0.50 & 50 & 3 & 250 & 125 & 212 & 30.80 & 2.00 & 1.46 & 2.550 & \\
\hline 35 & 63 & 0.50 & 50 & 3 & 250 & 125 & 212 & 30.80 & 3.00 & 1.46 & 2.000 & \\
\hline 36 & 60 & 0.50 & 30 & 3 & 375 & 60 & 340 & 35.0 & 2.00 & 3.44 & 5.340 & \\
\hline 37 & 60 & 0.75 & 30 & 3 & 375 & 60 & 340 & 33.0 & 2.00 & 3.44 & 4.430 & \multirow{3}{*}{$\begin{array}{c}\text { Tan et al. } \\
1993\end{array}$} \\
\hline 38 & 60 & 1.00 & 30 & 3 & 375 & 60 & 340 & 36.0 & 2.00 & 3.44 & 5.150 & \\
\hline 39 & 60 & 1.00 & 30 & 3 & 375 & 60 & 340 & 36.0 & 2.50 & 3.44 & 3.780 & \\
\hline 40 & 60 & 0.50 & 30 & 3 & 152 & 254 & 221 & 34.0 & 1.50 & 2.39 & 4.000 & \multirow{4}{*}{$\begin{array}{c}\text { Lim et al. } \\
1987\end{array}$} \\
\hline 41 & 60 & 1.00 & 30 & 3 & 152 & 254 & 221 & 34.0 & 1.50 & 2.39 & 4.380 & \\
\hline 42 & 60 & 1.00 & 30 & 3 & 152 & 254 & 221 & 34.0 & 2.50 & 2.39 & 2.450 & \\
\hline 43 & 60 & 1.00 & 30 & 3 & 152 & 254 & 221 & 34.0 & 3.50 & 2.39 & 2.000 & \\
\hline 44 & 80 & 1.50 & 76 & 2 & 610 & 305 & 546 & 32.8 & 2.80 & 1.84 & 2.030 & $\begin{array}{l}\text { Parra-Mon- } \\
\text { tesinos } 2006\end{array}$ \\
\hline 45 & 100 & 0.40 & 50 & 2 & 250 & 175 & 210 & 35.5 & 4.50 & 4.00 & 2.160 & \multirow{3}{*}{$\begin{array}{c}\text { Swamy } \\
\text { and Bahia } \\
1985\end{array}$} \\
\hline 46 & 100 & 0.80 & 50 & 2 & 250 & 175 & 210 & 37.4 & 4.50 & 4.00 & 3.100 & \\
\hline 47 & 100 & 1.20 & 50 & 2 & 250 & 175 & 210 & 39.8 & 4.50 & 4.00 & 3.130 & \\
\hline 48 & 100 & 1.00 & 50 & 2 & 300 & 55 & 265 & 40.9 & 3.40 & 4.31 & 4.030 & \multirow{4}{*}{$\begin{array}{c}\text { Swamy et } \\
\text { al. } 1993\end{array}$} \\
\hline 49 & 100 & 1.00 & 50 & 2 & 300 & 55 & 265 & 36.0 & 4.90 & 4.31 & 2.900 & \\
\hline 50 & 100 & 1.00 & 50 & 2 & 300 & 55 & 265 & 37.8 & 2.00 & 2.76 & 4.910 & \\
\hline 51 & 100 & 1.00 & 50 & 2 & 300 & 55 & 265 & 35.7 & 2.00 & 1.55 & 4.630 & \\
\hline 52 & 55 & 0.75 & 30 & 3 & 457 & 152 & 381 & 44.8 & 3.43 & 1.96 & 2.940 & \multirow{20}{*}{ Dinh 200} \\
\hline 53 & 55 & 0.75 & 30 & 3 & 457 & 152 & 381 & 44.8 & 3.43 & 1.96 & 2.750 & \\
\hline 54 & 55 & 1.00 & 30 & 3 & 457 & 152 & 381 & 38.1 & 3.50 & 1.96 & 3.030 & \\
\hline 55 & 55 & 1.00 & 30 & 3 & 457 & 152 & 381 & 38.1 & 3.50 & 1.96 & 3.100 & \\
\hline 56 & 55 & 1.50 & 30 & 3 & 457 & 152 & 381 & 38.1 & 3.43 & 2.67 & 3.380 & \\
\hline 57 & 55 & 1.50 & 30 & 3 & 457 & 152 & 381 & 45.0 & 3.43 & 2.67 & 3.280 & \\
\hline 58 & 55 & 1.50 & 30 & 3 & 457 & 152 & 381 & 45.0 & 3.43 & 2.67 & 3.260 & \\
\hline 59 & 80 & 1.00 & 60 & 3 & 457 & 152 & 381 & 49.2 & 3.43 & 2.67 & 3.770 & \\
\hline 60 & 80 & 0.75 & 30 & 3 & 457 & 152 & 381 & 43.4 & 3.43 & 1.96 & 3.310 & \\
\hline 61 & 55 & 0.75 & 30 & 3 & 689 & 203 & 457 & 50.8 & 3.50 & 2.06 & 2.930 & \\
\hline 62 & 80 & 0.75 & 60 & 3 & 689 & 203 & 457 & 28.8 & 3.50 & 2.06 & 2.810 & \\
\hline 63 & 55 & 0.75 & 30 & 3 & 689 & 203 & 457 & 42.3 & 3.50 & 1.56 & 2.780 & \\
\hline 64 & 80 & 0.75 & 60 & 3 & 689 & 203 & 457 & 29.6 & 3.50 & 1.56 & 2.140 & \\
\hline 66 & 80 & 0.75 & 60 & 3 & 689 & 203 & 457 & 29.6 & 3.50 & 1.56 & 1.790 & \\
\hline 66 & 55 & 1.5 & 30 & 3 & 689 & 203 & 457 & 44.5 & 3.50 & 2.06 & 3.50 & \\
\hline 67 & 55 & 1.50 & 30 & 3 & 457 & 152 & 381 & 38.1 & 3.43 & 2.67 & 2.560 & \\
\hline 68 & 100 & 0.80 & 50 & 2 & 250 & 175 & 210 & 38.2 & 4.50 & 3.05 & 3.210 & \\
\hline 66 & 100 & 1.00 & 50 & 2 & 300 & 55 & 265 & 35.6 & 2.00 & 4.31 & 5.480 & \\
\hline 70 & 100 & 1.00 & 50 & 2 & 300 & 55 & 265 & 33.1 & 3.40 & 2.76 & 3.110 & \\
\hline 71 & 100 & 1.00 & 50 & 2 & 300 & 55 & 265 & 35.9 & 4.90 & 2.76 & 2.920 & \\
\hline
\end{tabular}

Table 1: Experimental data (contd.). 
Table 2 presents the range, arithmetic mean $(\mu)$, standard deviation $(\sigma)$ and the coefficient of variance $(\mathrm{COV})$ of the collected data.

\begin{tabular}{cccccccccccc}
\hline & $L_{f} / d_{f}$ & $\begin{array}{c}\rho_{f} \\
(\%)\end{array}$ & $\begin{array}{c}L_{f} \\
(\mathrm{~mm})\end{array}$ & $G$ & $\begin{array}{c}h \\
(\mathrm{~mm})\end{array}$ & $\begin{array}{c}b \\
(\mathrm{~mm})\end{array}$ & $\begin{array}{c}d \\
(\mathrm{~mm})\end{array}$ & $\begin{array}{c}f_{c}^{\prime} \\
(\mathrm{MPa})\end{array}$ & $a / d$ & $\begin{array}{c}\rho \\
(\%)\end{array}$ & $\begin{array}{c}v_{u} \\
(\mathrm{MPa})\end{array}$ \\
\hline No. & & & & & Training data & & & & & \\
Min. & 55 & 49 & 49 & 49 & 49 & 49 & 49 & 49 & 49 & 49 & 49 \\
Max. & 100 & 2.00 & 60 & 3 & 610 & 254 & 558 & 68.60 & 4.00 & 6.59 & 5.990 \\
range & 45 & 2.00 & 30 & 2 & 458 & 204 & 418 & 37.80 & 3.69 & 5.13 & 3.990 \\
$\mu$ & 66 & 0.94 & 36 & 3 & 364 & 144 & 319 & 44.04 & 2.75 & 2.51 & 3.346 \\
$\sigma$ & 14.69 & 0.44 & 9 & 0.66 & 148 & 46 & 124.5 & 11.23 & 0.89 & 1.30 & 0.850 \\
COV & 0.22 & 0.47 & 0.25 & 0.24 & 0.41 & 0.32 & 0.39 & 0.26 & 0.32 & 0.52 & 0.260 \\
\hline & & & & & Testing data & & & & & \\
\hline No. & 21 & 21 & 21 & 21 & 21 & 21 & 21 & 21 & 21 & 21 & 21 \\
Min. & 55 & 0.40 & 30 & 2 & 250 & 55 & 210 & 28.80 & 2.00 & 1.55 & 2.030 \\
Max. & 100 & 1.50 & 76 & 3 & 689 & 305 & 546 & 50.80 & 4.90 & 4.31 & 5.480 \\
range & 45 & 1.10 & 46 & 1 & 439 & 250 & 336 & 22.00 & 2.90 & 2.76 & 3.450 \\
$\mu$ & 83 & 0.93 & 46 & 2 & 412 & 126 & 328 & 36.89 & 3.30 & 2.99 & 3.546 \\
$\sigma$ & 19.59 & 0.27 & 12.76 & 0.51 & 176 & 79 & 104 & 4.92 & 1.05 & 0.98 & 1.07 \\
COV & 0.24 & 0.29 & 0.28 & 0.21 & 0.43 & 0.63 & 0.32 & 0.13 & 0.32 & 0.33 & 0.30 \\
\hline \hline
\end{tabular}

Table 2: Statistics of experimental data

\section{RESULTS AND DISCUSSION}

\subsection{Analysis and Validity of the Model}

The performance of ANN-10 was evaluated by conducting error analysis. Table 3 shows the summary of the error analysis of ANN-10 for the training and testing data sets. In this table, the minimum, maximum, $\mu, \sigma$ and COV are given for: 1) the square error, 2) the absolute error and 3) the predicted to experimental values. For the training data set, the average of square error, absolute error and predicted to experimental values ratio were 0.032, 0.106, and 1.002, respectively. However, they were $0.029,0.112$ and 1.002, respectively, for the testing data set. Figure $4^{\sim} 5$ show the performance of $\mathrm{ANN}-10$ in predicting the ultimate shear strength of SFRC beams for the training and testing data sets, respectively. From Figure 4 and Figure 5, it can be seen that ANN-10 has excellent predictive performance for the prediction of the training and testing data sets with more than 95\% correlation coefficient. These strong correlations establish the validity of ANN-10 for the prediction of the ultimate shear strength of SFRC without web reinforcement. 


\begin{tabular}{cccc}
\hline \hline & & Training data set & Testing data set \\
\hline Min. & $15.1451 \times 10^{-6}$ & $0.251 \times 10^{-6}$ \\
Max. & 0.248 & 0.179 \\
& $\boldsymbol{\sigma}$ & 0.032 & 0.029 \\
& COV. & 0.067 & 0.048 \\
& Min. & 2.088 & 1.676 \\
Max. & $38.913 \times 10^{-3}$ & $5.006 \times 10^{-3}$ \\
& $\mu$ & 0.498 & 0.424 \\
Absolute error & $\sigma$ & 0.106 & 0.112 \\
& COV. & 0.144 & 0.127 \\
& Min. & 1.366 & 1.138 \\
& Max. & 0.856 & 0.918 \\
& $\mu$ & 1.181 & 1.076 \\
& & 1.002 & 1.002 \\
& & 0.060 & 0.037 \\
& & 0.059 & 0.037 \\
\hline \hline
\end{tabular}

Table 3: Summary of error analysis.

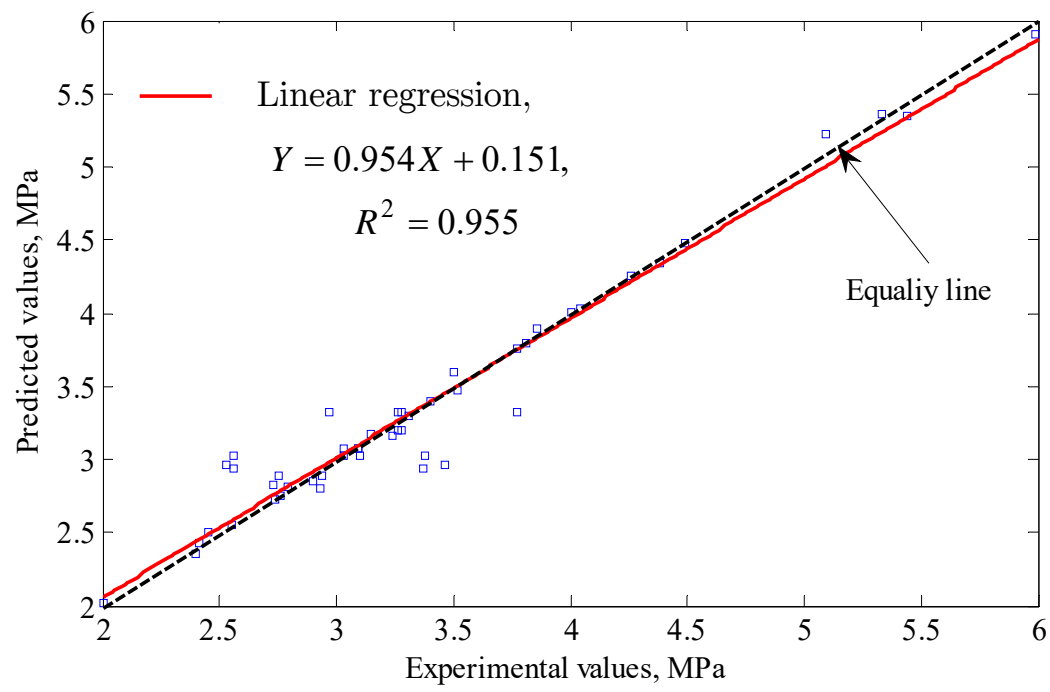

Figure 4: Experimental values vs. predicted values of ultimate shearing strength for the training data set 


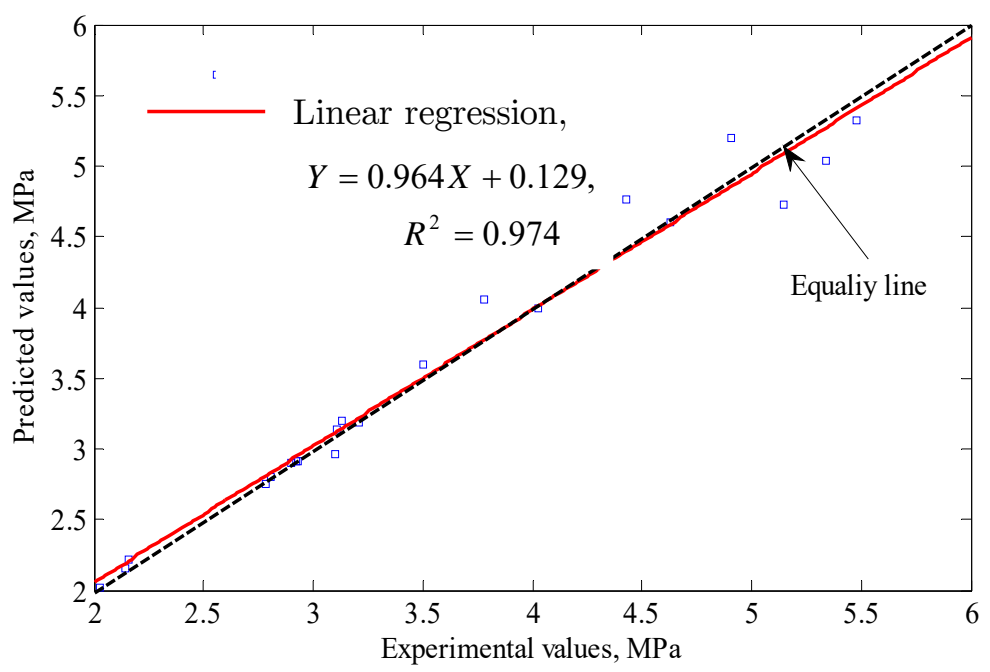

Figure 5: Experimental values vs. predicted values of ultimate shearing strength for the testing data set

\subsection{Parametric Study}

The network ANN-10 was utilized to study the influence of the individual properties of the fiber on the ultimate shear strength of SFRC beams without web reinforcement. At different shear span to effective depth ratios $a / d$, the effect of fiber volume content, aspect ratio and length were studied by varying their values. To investigate the influence of the type of fiber, the fiber geometry code was kept constant for different shear spans to effective depth ratios.

\subsubsection{Influence of Volume Content of Fibers}

Figure 6 shows the influence of $V_{f}$ on $v_{u}$ for SFRC beams without web reinforcement for different $a / d$ values. The kept-constant properties of the investigated beams are shown in this figure. For deep beams $(a / d \leq 2)$, it can be seen from this figure that $v_{u}$ drastically increases as $V_{f}$ increases to a certain value (about 1\%), after which $v_{u}$ increases marginally. However, for shallow beams $(a / d>2)$, little improvement of $v_{u}$ with increasing $V_{f}$ was observed. It is worth noting that a similar behavior for SFRC beams was reported by Lim and Oh (1999), and Cucchiara et al. (2004). They showed that the inclusion of an appropriate volume content of steel fiber could increase the ultimate shear strength more than the flexural strength of longitudinally reinforced SFRC beams, which alters the ductile shear failure mode into the flexure model of failure.

In addition from Figure 6, it can be seen that for $V_{f}<0.5 \%, v_{u}$ increases as $a / d$ increases, however, this behavior is changed for $V_{f}>0.5 \%$. In other words, for $V_{f}<0.5 \%$ the shallower beam (has the largest $a / d)$ has the highest $v_{u}$ compared to other beams. However, for $V_{f}>0.5 \%$ the deeper beam (has the smallest $a / d$ ) has the highest $v_{u}$. This finding demonstrates that the addition of about $0.5 \%$ or more steel fibers in reinforced concrete beams alters the brittle shear behavior and 
sudden failure of beams, especially for deep beams $(a / d \leq 2.0)$. In addition, this result confirms the capability of steel fibers to increase the ultimate shear strength of beams, in a way that they can replace the nominal web reinforcement as reported by various researchers (Furlan and de Hanai 1997; Imam et al. 1997; Lim and Oh 1999; Dinh 2009). The improvement in $v_{u}$ due to the increase $V_{f}$ is attributed to the increase in the crack bridging capacity at the post-cracking stage, which enhances the overall mechanical performance of the concrete.

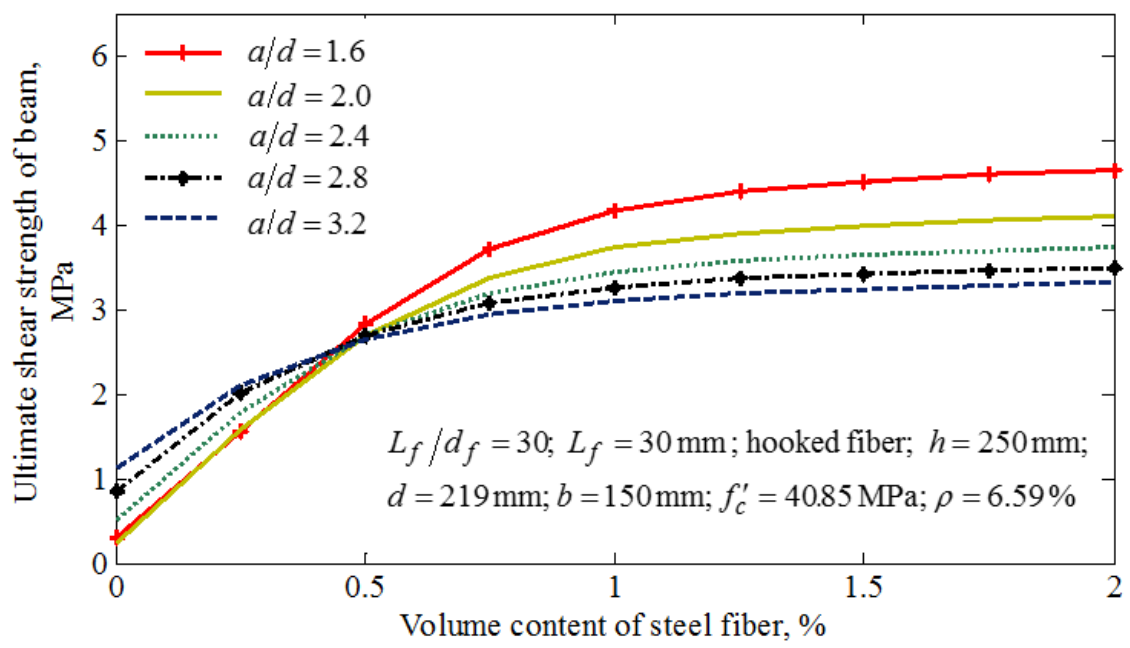

Figure 6: Influence of volume content of fiber on the ultimate shear strength of SFRC beams without web reinforcement

\subsubsection{Influence of Aspect Ratio of Fibers}

Figure 7 shows the influence of $L_{f} / d_{f}$ on $v_{u}$ of SFRC beams without web reinforcement for different $a / d$ values. The constant properties of the studied SFRC beams are given in this figure. As can be seen from this figure, increasing $L_{f} / d_{f}$ from 60 to 100 causes a $24^{\sim} 32 \%$ increase for $v_{u}$ of shallow and deep beams. In addition, the improvement of $v_{u}$ due to increasing $L_{f} / d_{f}$ in deep beams are more than the same for shallow beams. The improvement in $v_{u}$ due to an increase in $L_{f} / d_{f}$ is attributed to the increase in the fiber-concrete matrix interface.

\subsubsection{Influence of Length of Fibers}

Figure 8 shows the influence of $L_{f}$ on $v_{u}$ of SFRC beams without web reinforcement for different $a / d$ values. The properties of the studied SFRC beams are given in this figure. As can be seen from this figure, increasing $L_{f}$ from 30 to 60 causes a $5^{\sim} 20 \%$ increase in $v_{u}$ for deep and shallow beams. Unlike the change in $v_{u}$ due to $L_{f} / d_{f}$, the percentage increase in $v_{u}$ for shallow beams is more than that for deep beams. This demonstrates that the influence of $L_{f}$ is more pronounced for shallow 
beams compared to deep beams. For these particular SFRC beams, it seems that the optimum fiber length for the investigated beam is $45 \mathrm{~mm}$.

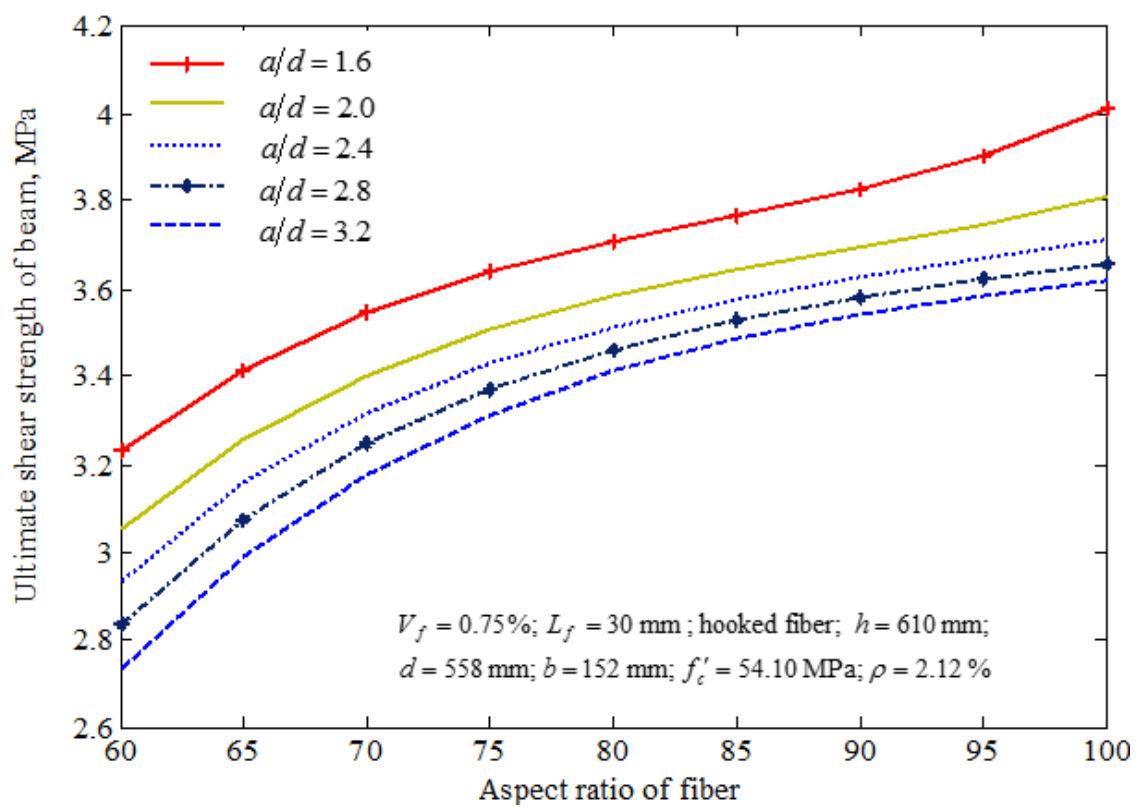

Figure 7: Influence of aspect ratio of fiber on the ultimate shear strength of SFRC beams without web reinforcement

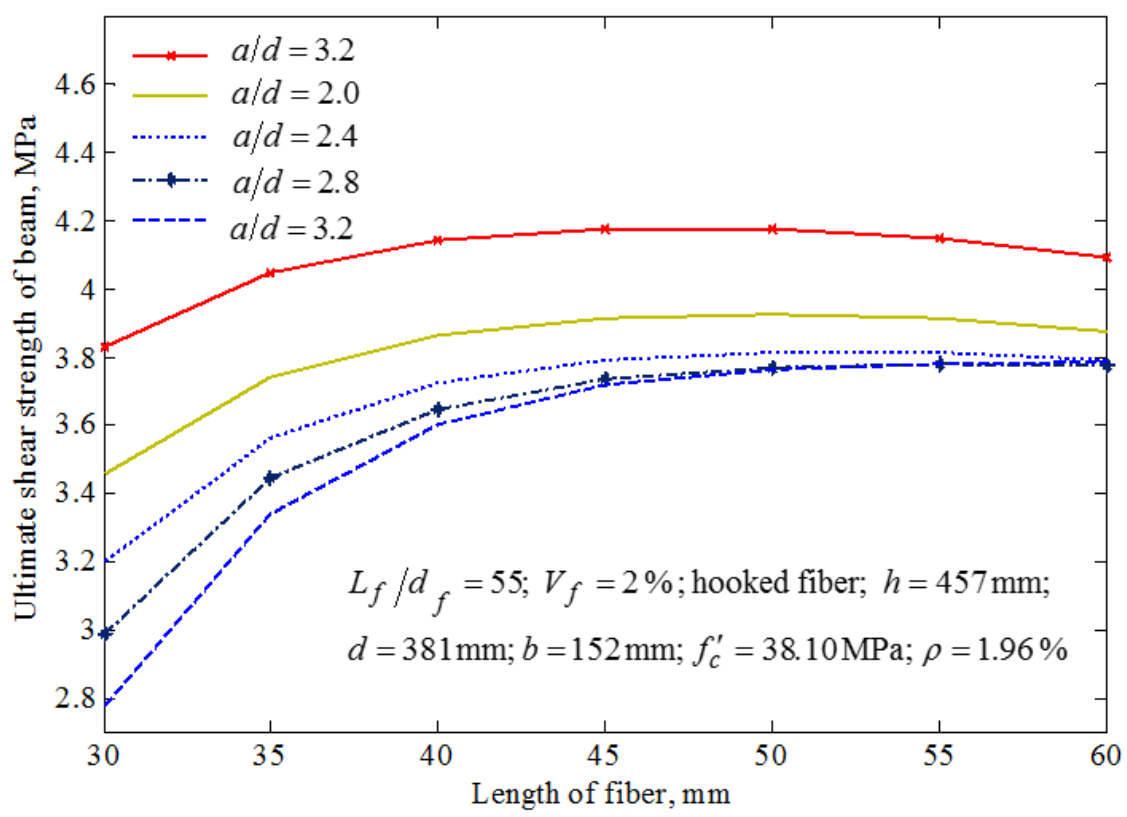

Figure 8: Influence length of fiber on the ultimate shear strength of SFRC beams without web reinforcement 


\subsubsection{Influence of Type of Fiber}

Figure 9 shows the influence of the type of fiber on $v_{u}$ of SFRC beams without web reinforcement for different $a / d$ values. The properties of the studied SFRC beams are given in this figure. As can be seen from this figure for deep beams $(a / d<2)$, all types of fiber have almost the same influence on $v_{u}$. However, for straight fibers, $v_{u}$ is drastically decreased as the $a / d$ increased for shallow beams $(a / d>2)$. This demonstrated that straight fibers cannot be used as minimum web reinforcement for shallow beams.

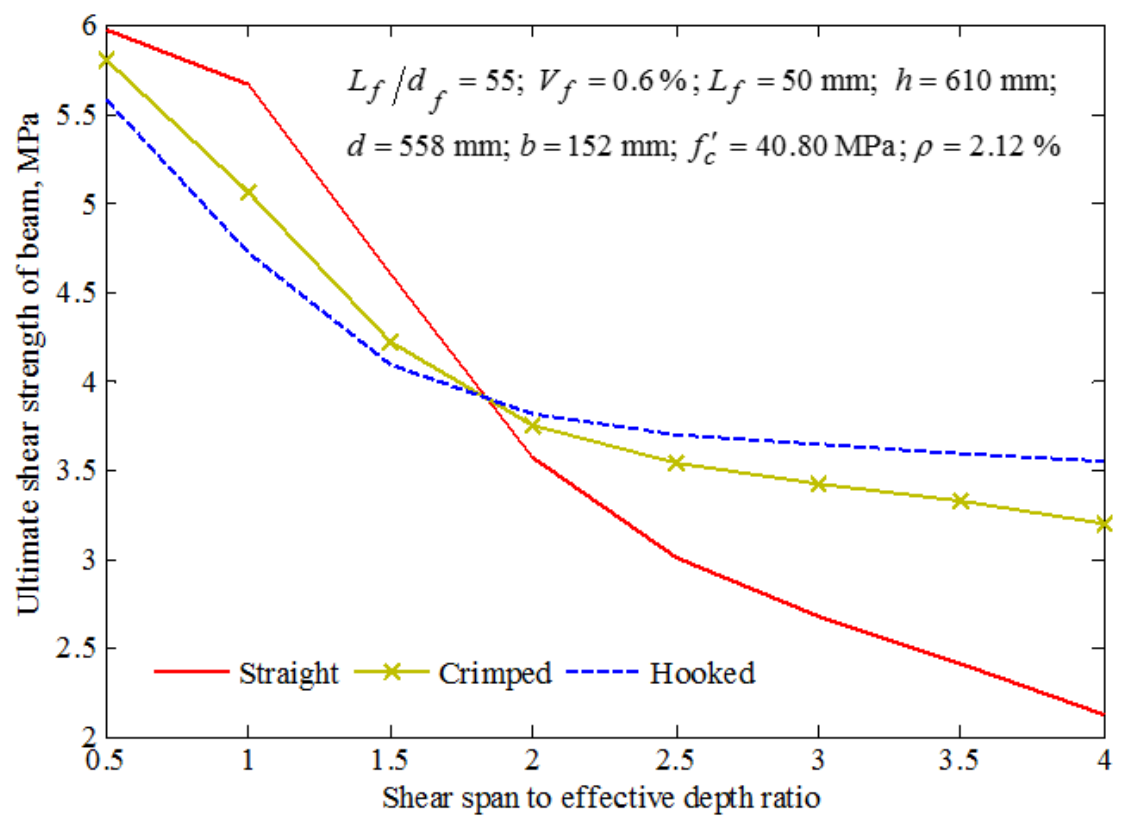

Figure 9: Influence type of fiber on the ultimate shear strength of SFRC beams without web reinforcement

\section{CONCLUSIONS}

Various researchers have developed regression analysis-based models for the prediction of the ultimate shear strength of SFRC beams. However, none of these models can perfectly predict the ultimate shear strength of SFRC beams. ANNs have been utilized in various fields including civil engineering to correlate the outputs and inputs of highly nonlinear problems. Nevertheless, very little research has been undertaken on the potential of using ANNs for the prediction of the ultimate shear strength of SFRC beams. This study is aimed at to develop a rational numerical model for the prediction of the ultimate shear strength of SFRC beams. From this study, the following conclusions were drawn:

A multilayer feed forward neural network (ANN-10) with a back propagation training algorithm and 14-neurons of two hidden layers was developed to predict the ultimate shear strength of SFRC beams. Experimental data of 70 SFRC beams reported in the technical literature by 11 research groups were utilized to train and test the ANN-10. The input parameters of ANN-10 were: i) the 
properties of fiber (type, volume content, aspect ratio and length), ii) the properties the section (Overall depth, width, and effective depth), and, iii) the properties of the beam (shear span-toeffective depth ratio, percentage of longitudinal reinforcement, and the cylindrical compressive strength of concrete). ANN-10 exhibited excellent predictive performance for the prediction for both the training and testing data sets with 1.002 average of the predicted to experimental values. The successful performance of ANN-10 has established the favorable potential of ANNs to simulate of the complex shear behavior of SFRC beams.

A significant increase in the ultimate shear strength occurs for deep SFRC beams with increasing the fiber content. However, little increase in the ultimate shear strength occurred for shallow beams. In addition, the inclusion of $0.5 \%$ or more volume of steel fibers to fabricate the SFRC deep beams altered its failure mode from brittle shear to ductile flexure. In this study, up to $32 \%$ improvement of the ultimate shear strength of SFRC beams was observed by increasing the aspect ratio of the fiber from 60 to 100. The strength improvement in the deep beams was more pronounced than in the shallow beams. By increasing the fiber length from $30 \mathrm{~mm}$ to $60 \mathrm{~mm}$, a $5^{\sim} 20 \%$ increase in the ultimate shear strength of SFRC beams was observed. The fiber length influences the flexural strength of the SFRC beams more than its shear strength. Straight, crimped and hooked fibers have almost a similar influence on the shear strength of SFRC beams for deep beams. However, the straight rounded fibers have very little influence on the ultimate shear strength of shallow beams.

\section{Acknowledgements}

The Author extends his appreciation to the Deanship of Scientific Research at King Saud University for funding the work through the research group project No. RGP-VPP-105.

\section{References}

Adebar P., Mindess S., Pierre D., and Olund B. (1997). "Shear tests of fiber concrete beams without stirrups." ACI Structural Journal 94(1).

Adhikary B. and Mutsuyoshi H. (2006). "Prediction of shear strength of steel fiber RC beams using neural networks." Construction and Building Materials 20(9): 801-811. doi.org/10.1016/j.conbuildmat.2005.01.047.

Al-Ta'an S. and Al-Feel J. (1990). "Evaluation of shear strength of fibre-reinforced concrete beams." Cement and Concrete Composites 12(2): 87-94. doi.org/10.1016/0958-9465(90)90045-Y.

Bashir R. and Ashour A. (2012). "Neural network modelling for shear strength of concrete members reinforced with FRP bars." Composites Part B: Engineering 43(8): 3198-3207. doi.org/10.1016/j.compositesb.2012.04.011.

Cucchiara C., La Mendola L. and Papia, M. (2004). "Effectiveness of stirrups and steel fibres as shear reinforcement." Cement and concrete composites 26(7): 777-786. doi.org/10.1016/j.cemconcomp.2003.07.001.

Dinh H. (2009). Shear behavior of steel fiber reinforced concrete beams without stirrup reinforcement, PhD thesis, University of Toronto.

Furlan S. and de Hanai B. (1997). "Shear behaviour of fiber reinforced concrete beams." Cement and concrete composites 19(4): 359-366. doi.org/10.1016/S0958-9465(97)00031-0.

Hegazy T., Tully S., and Marzouk H. (1998). "A neural network approach for predicting the structural behavior of concrete slabs." Canadian Journal of Civil Engineering 25(4): 668-677. 
Imam M., Vandewalle L., Mortelmans F., (1997). "Shear domain of fibre-reinforced high-strength concrete beams." Engineering structures 19(9): 738-747. doi.org/10.1016/S0141-0296(96)00150-2.

Jha G. (2007). "Artificial Neural Networks." Indian Agricultural Research Institute: 1-10.

Khuntia M., Stojadinovic B., and Goel S. (1999). "Shear strength of normal and high-strength fiber reinforced concrete beams without stirrups." ACI Structural Journal 96(2).

Kwak Y., Eberhard M., Kim W. Kim, J. (2002). "Shear strength of steel fiber-reinforced concrete beams without stirrups." ACI Structural Journal 99(4).

Lee S. and Lee C. (2014). "Prediction of shear strength of FRP-reinforced concrete flexural members without stirrups using artificial neural networks." Engineering structures 61: 99-112. doi.org/10.1016/j.engstruct.2014.01.001.

Lim D. and Oh B. (1999). "Experimental and theoretical investigation on the shear of steel fibre reinforced concrete beams." Engineering structures 21(10): 937-944. doi.org/10.1016/S0141-0296(98)00049-2.

Lim T., Paramasivam P. and Lee S. (1987). "Shear and moment capacity of reinforced steel-fibre-concrete beams." Magazine of concrete research 39(140): 148-160. doi.org/10.1680/macr.1987.39.140.148.

Mansur M., Ong K. and Paramasivam, P. (1986). "Shear strength of fibrous concrete beams without stirrups." Journal of structural engineering 112(9): 2066-2079. doi.org/10.1061/(ASCE)0733-9445(1986)112:9(2066).

Mashrei M., Seracino R. and Rahman, M. et al. (2013). "Application of artificial neural networks to predict the bond strength of FRP-to-concrete joints." Construction and Building Materials 40: 812-821. doi.org/10.1016/j.conbuildmat.2012.11.109.

Naik, U. and S. Y. Kute (2014). "Effect of Shear Span to Depth Ratio on Shear Strength of Steel Fiber Reinforced High Strength Concrete Deep Beam using ANN". International Journal of Engineering Research and Technology, ESRSA Publications.

Narayanan R. and I. Darwish (1987). "Use of steel fibers as shear reinforcement." ACI Structural Journal 84(3).

Parra-Montesinos, G. (2006). "Shear strength of beams with deformed steel fibers." Concrete International-Detroit28(11): 57.

Perera R., M. Barchín, Arteaga, A., and De Diego, A. (2010). "Prediction of the ultimate strength of reinforced concrete beams FRP-strengthened in shear using neural networks." Composites Part B: Engineering 41(4): 287-298. doi.org/10.1016/j.compositesb.2010.03.003.

Roberts T. and N. Ho (1982). "Shear failure of deep fibre reinforced concrete beams." International Journal of Cement Composites and Lightweight Concrete 4(3): 145-152. doi.org/10.1016/0262-5075(82)90040-9.

Sanad, A. and M. Saka (2001). "Prediction of ultimate shear strength of reinforced-concrete deep beams using neural networks." Journal of structural engineering 127(7): 818-828. doi.org/10.1061/(ASCE)0733-9445(2001)127:7(818).

Sharma A. (1986). "Shear strength of steel fiber reinforced concrete beams." ACI journal 83(4): 624-628.

Swamy R. and H. Bahia (1985). "The effectiveness of steel fibers as shear reinforcement." Concrete International $7(3): 35-40$.

Swamy R., Jones R., and Chiam, A. (1993). "Influence of steel fibers on the shear resistance of lightweight concrete I-beams." ACI Structural Journal 90(1).

Tan, K., Murugappan K., and Paramasivam, P. (1993). "Shear behavior of steel fiber reinforced concrete beams." ACI Structural Journal 90(1). 